\title{
Energy recovery in SUDS towards smart water grids: A case study
}

\author{
Helena M. Ramos ${ }^{\mathrm{a}, *}$, Charlotte Teyssier ${ }^{\mathrm{b}}$, Irene Samora ${ }^{\mathrm{a}}$, Anton J. Schleiss ${ }^{\mathrm{c}}$ \\ a Civil Engineering Department, Instituto Superior Técnico, University of Lisbon, Portugal \\ ${ }^{\mathrm{b}}$ Engineering School Centrale Nantes, France

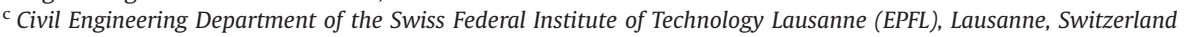

\section{H I G H L I G H T S}

- An innovative solution for Sustainable Urban Drainage Systems (SUDS).

- Use of retention ponds to reduce risks of urban flooding while producing energy.

- Use of recently developed hydropower converters for low heads.

- Solution to be integrated in future smart water networks for increasing efficiency.

- Water and energy nexus for sustainable operation towards future smart cities.

\section{A R T I C L E I N F O}

\section{Article history:}

Received 9 January 2013

Accepted 2 August 2013

\section{Keywords:}

Energy recovery

SUDS

Smart water grids.

\begin{abstract}
A B S T R A C T
The development of a methodology for urban flood adaptation and energy recovery solutions is resting on the concept of Sustainable Urban Drainage Systems (SUDS) as a measure to reduce risks of urban flooding while fully utilizing the available resources. Flood drainage systems are infrastructures essential in urban areas, which include retention ponds that can be used as water storage volumes to damp floods and simultaneously to produce energy, constituting innovative solutions to be integrated in future smart water grid's designs.

The consideration of urban flooding as a problem caused by excess water that can be harvested and reused is expected to provide a comprehensive representation of a water-energy nexus for future urban areas. The study comprises an optimization of energy recovery in SUDS of a small district area of Lisbon down-town through the use of a low-head hydropower converter.

The status-quo solution based on a basin catchment for the average expected runoff is analysed, with influence of the tidal backwater effect of the Atlantic Ocean which causes difficulties to the drainage of excess flow. The methodology used to reach the flow damping and the optimized solution for energy production is presented.
\end{abstract}

(c) 2013 Elsevier Ltd. All rights reserved.

\section{Introduction}

Urban flooding is the result of rainfall exceeding the drainage capacity. The overflowing of roads, properties and infrastructures causes not just high damages but also distress and even life losses. Moreover, this urban flow is a major source of pollution, picking up and transporting harmful substances and posing risks to public health and to the environment.

A common solution for this problem is the storage of the water excess in retention ponds. These reservoirs usually discharge into the environment or lead the water to treatment plants.

What poses a new challenge is the fact that the impact of flooding in urban areas may be worsened in the near future, due to the

\footnotetext{
*Corresponding author. Tel.: + 351 218418151; fax: + 351218497650.

E-mail addresses: hr@civil.ist.utl.pt, hramos.ist@gmail.com (H.M. Ramos).
}

augmentation of impermeable areas. In fact the European Environment Agency (EEA) confirms that the urban space is increasing, the green areas are being reduced and a greater number of people are living in urban areas than in rural regions. Europe is one of the continents with the highest rate of urbanization, with about $75 \%$ of the population living in urban areas, and recent studies reveal that this scenario could increase to $80 \%$ in 2020.

The EEA also states that the space occupied by urban areas is increasing faster than the population itself. It is expected that, between 2000 and 2030, the world population will have increased approximately $72 \%$, while, for the same period, it is expected an increase of $175 \%$ of urban areas with 100000 or more inhabitants. In Fig. 1 it is shown the urban growth expected in 2030.

This growing urbanization is contributing to reduce the soil absorption capacity and storage of stormwater, which has lead, together with the ageing of the existing drainage infrastructure, to 
an increase in the cost of flood management (Wegehenkel and Kersebaum, 2008; Einfalt et al., 2009; Tingsanchali, 2012; Makropoulos et al., 2008). To tackle this challenge, innovative and sustainable urban drainage systems and methodologies are needed.

The design of urban drainage traditionally sought to catch the excess runoff and lead it out of the cities, according to sanitary and security precepts. However, nowadays urban drainage can be seen in a more broad vision, as a part of the water-energy nexus. This nexus refers to the fact that water and energy are basic needs with similar demands and, consequently, should have an integrated base-management. Even though these are some of the essential goods in modern societies, few authors have presented globalscale water and energy foot-printing analyses (Vieira and Ramos, 2008; Ramos and Ramos, 2009; Hoekstra et al., 2009; Ramos et al., 2011) being traditionally managed independently (Beaulieu, 2010; Lindström and Granit, 2012; Howe and Mitchell, 2012).

The new approach of having a joint management in sustainable urban drainage systems (SUDS) will not only assure that the system is designed to face the likely hydrological extreme events of the area but also to increase the penetration of renewable energy sources, which is particularly relevant in a context with increased scarcity of primary resources (Pender and Néelz, 2007; Bizikova et al., 2008; Breinholt et al., 2008; UK.Lee et al., 2012).

In this context, the flood-control and drainage systems can be seen as new hydropower opportunities. Hydropower is the most used source of renewable energy in the world and it can help mitigate the climate changes by cutting our dependence on carbon-based fuels (Sommers, 2004; San Bruno et al. 2008; Wiemann et al., 2009).

The integration of hydropower production in SUDS will be sensitive to total runoff, to the timing of the runoff and to the geometry of each retention pond in each drainage system. Additionally, specific energy converters for small heads are needed for the feasibility of such systems.

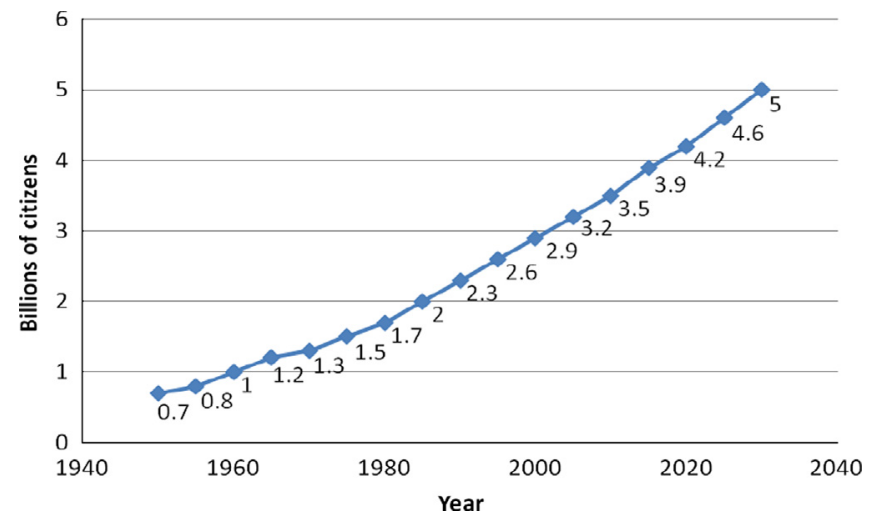

Fig. 1. Prediction of urban growth in the world.

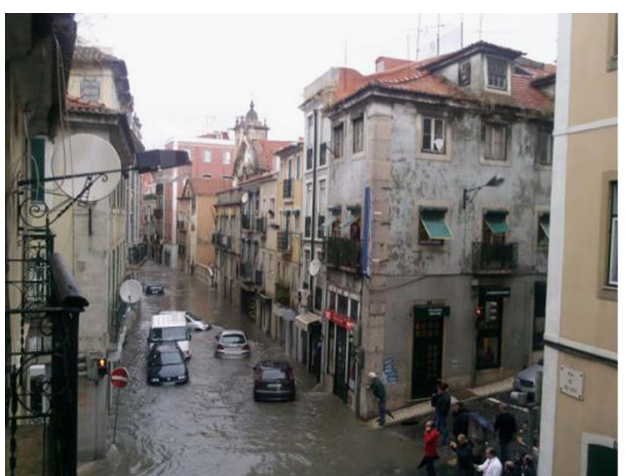

The development of hydropower converters for very low heads has been in progress under the European project HYLOW (20092012), where studies of new systems were gathered to exploit the energy created by small waterfalls or to take the advantage of nonnegligible available flow energy in any water pipe system. Two of low head energy converters from the HYLOW project research are worthy of mention in this context: first, the hydraulic pressure machine (HPM), which was developed at the University of Southampton in the UK (Senior, et al., 2008), is a waterwheel working for small heads, from 1 to $2.5 \mathrm{~m}$, and flow values between 1 and $2 \mathrm{~m}^{3} / \mathrm{s}$, depending on the size of the machine; second, as an alternative to this device, a tubular propeller with 5 blades (TP5B) and an internal diameter of $100 \mathrm{~mm}$ was developed at the Instituto Superior Técnico, Technical University of Lisbon, and it is suitable for heads between 0.5 and $10 \mathrm{~m}$ and flow values in the range of 3 to $16 \mathrm{l} / \mathrm{s}$ (Ramos et al., 2009, 2012b, 2012c, 2013; Caxaria et al., 2011). These new technologies can be applied to existing water systems, with the purpose of producing energy (Ramos et al., 2009; Madsen et al., 2009), being the drainage systems one example of possible applications. These converters have significant low-costs of installation and maintenance which makes them largely suitable and attractive as a sustainable solution.

Hence, the purpose of the present study is to optimize the energy production in the outlet of a retention pond through a micro-hydro converter specifically suitable for low heads. A case study was chosen based on a previously calibrated Mike Basin model (Ramos et al., 2012a), that characterizes the precipitationrunoff relation based on rainfall, evaporation and territory properties. The studied area is a district of Lisbon which has been facing several serious flood problems (Fig. 2) thanks to its location in a downtown area, near the Tagus River and the Atlantic Ocean.

The analysis is based on the settlement of a power target demand and on the design of the volume, the shape and the depth of the retention pond, as well as on the control of the water discharge.

Since the use of reservoirs involved with flood risk assessment has been documented in some references (Eum et al., 2012; Talukdar et al., 2011), the combination of flood control with energy generation is the novelty proposal in this research. The introduction of the concept of SUDS connected with water-energy nexus is an intended innovation, which leads to proposing joint management methods and design implications to optimize water/power systems. The goal is to present a new methodology for microhydro solution by sizing both the volume and the water height in flood control ponds in order to maximise the energy production.

\section{System modelling}

\subsection{Brief description}

Mike Basin (MB) is a water management network model that analyses water resources and water uses. It was created to solve water

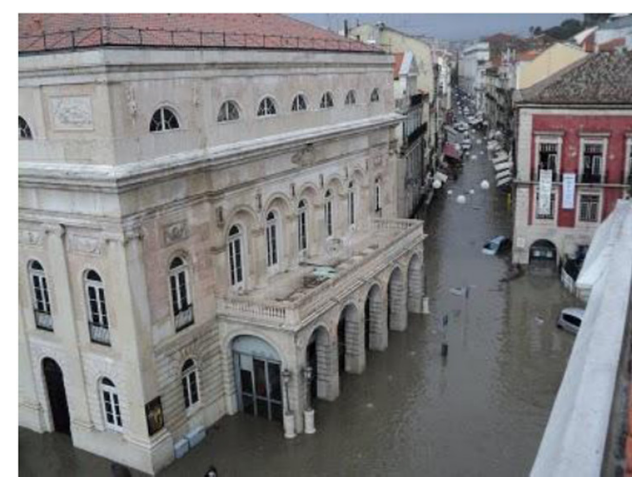

Fig. 2. Example of flood events in Lisbon (October 2010) 


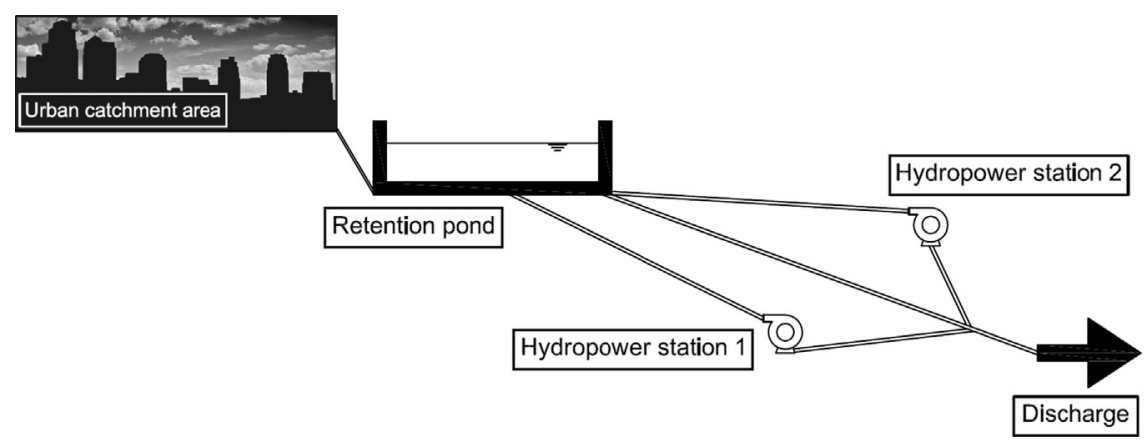

Fig. 3. Simplified representation of a retention pond and hydropower-base system.

sharing problems and environmental issues in several application fields. Rivers and channels are represented by branches on the system network and the nodes represent confluences, diversions and water facilities such as reservoirs and hydropower stations (DHI, 2009). The simplified configuration of the studied system is presented in Fig. 3.

Ponds allow storage rainfall from a catchment to avoid floods and $\mathrm{MB}$ tools contain several multi-purpose reservoir systems. A rule curve reservoir is used in this study and the characteristics of the retention pond are user defined. The most important parameters are its size and shape and the rules to control its behaviour, such as the flood control level and the top of dead-end storage. The flood control level is set at the height of each pond as a weir crest level.

The study is based on two hydropower stations which are located downstream of a pre-defined retention pond (Fig. 3). Power outputs are calculated as function of the outlet discharge and the net head is created from the water level inside the pond.

Power Target demands are considered for each hydropower station. The first one has priority over the second and the target demand is stated constant. For the second one, the target demand is monthly variable, depending on the season. The targets control the generated power and, consequently, the turbine discharge. The simulator model is able to control the power target demands according to the water level. The power generated is allowed to exceed the demand when the "surplus capacity" is accepted. More precisely, below a characteristic water level, called reduction level, the target demand is affected by a reduction factor (RF) between 0 and 1 . This allows keeping a certain head of water in the reservoir and, as a result, to optimise the energy production, for a given RF. In practice, the pond is provided with an extra control system.

In this study, the reduction rule is set the same for each hydropower station (1 and 2). The reduction level is fixed at two thirds of the reservoir height (i.e. $6.7 \mathrm{~m}$ for the $10 \mathrm{~m}$-high retention pond and $2 \mathrm{~m}$ for the $3 \mathrm{~m}$-high pond, respectively) and for the $\mathrm{RF}$ a constant value of 0.8 was considered. The control in both water outlets prevented the outlet flow from exceeding the maximum turbine discharge assumed by each hydropower station.

\subsection{Model simulation}

MB simulates the runoff on a catchment taking into account the hydrological cycle, the type of soil and the provision of water, such as the over-land flow, base-flow and inter-flow. The supply of water comes from rainfall and snow melt, being also affected by the evaporation. The soil is divided into four inter-connected zones: surface, groundwater and snow storage. The characteristics of each zone are defined according to the type of area under analysis, which is, in this case, a down-town urban zone. In these circumstances, surface storage, interflow and base flows are considered negligible and, from that premise, the model is then calibrated. The pond at the starting point is considered dry. The rainfall is based on data belonging to the meteorological institute of Portugal (Meteo.pt, 2012), from the station of Lisbon.
Simulations are run for a series of daily rainfall. This consists on getting the water management based on inputs and several rules which control the water balance. Calculations are done for the flow in each node, for the storage and the water level inside the retention pond and for the generated power, as well as for the power deficit of each hydropower station. The objective is to analyse the electricity production capacity regarding the generated power, the power deficit and the water turbine discharge. The aim of each retention pond is to avoid floods, which consequently emphasizes the importance of controlling the water turbine discharge.

\section{Micro-hydro implementation}

Integrated in the EU-HYLOW Project developments, a novel hydropower converter for open channel flows and very small head differences of 1 to $3 \mathrm{~m}$ and flow rates from 50 to $420 \mathrm{l} / \mathrm{s}$ with $0.97 \mathrm{~m}$ of wheel width was developed at Southampton University in cooperation with the Technical University of Darmstadt (Senior et al., 2011; Schneider et al., 2011) (see Fig. 4). A theoretical approach was developed to assess the performance characteristics of this Hydrostatic Pressure Machine (HPM).

The following results can be summarised as follows:

- diagonal blades mounted in an angle of 20 degrees on the hub were identified as the best combination of simple geometry and efficiency;

- a flume width ratio of approx. 1:1.3 is recommended as most efficient and economic set-up;

- minimizing the gap between the tip of the blade and the curved bottom section, a flexible rubber band increases the available power output and the efficiency significantly;

- an increase in head difference between the up- and downstream water levels results in a significant increase in power

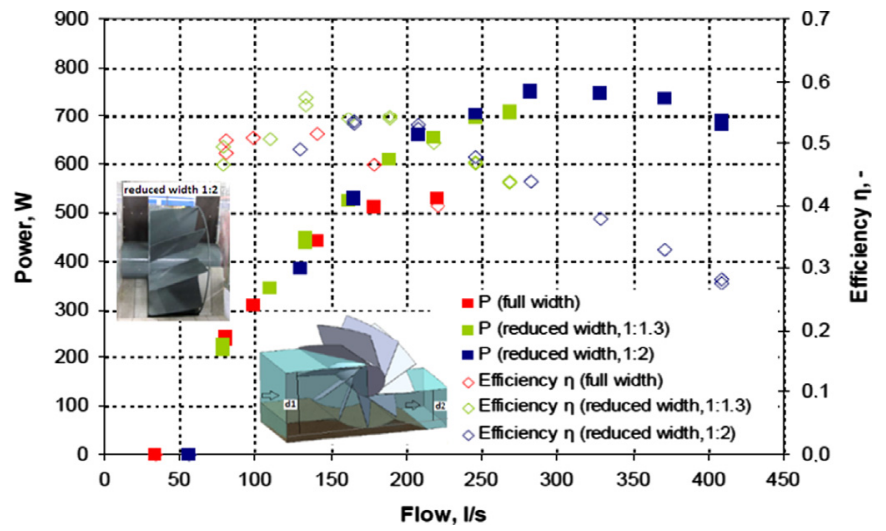

Fig. 4. Performance curves obtained in lab: diagonal blades with different ratios of HPM to flume width; $d 1=0.815 \mathrm{~m}, d 2=0.2 \mathrm{~m}$ (adapted from Schneider et al., 2011). 

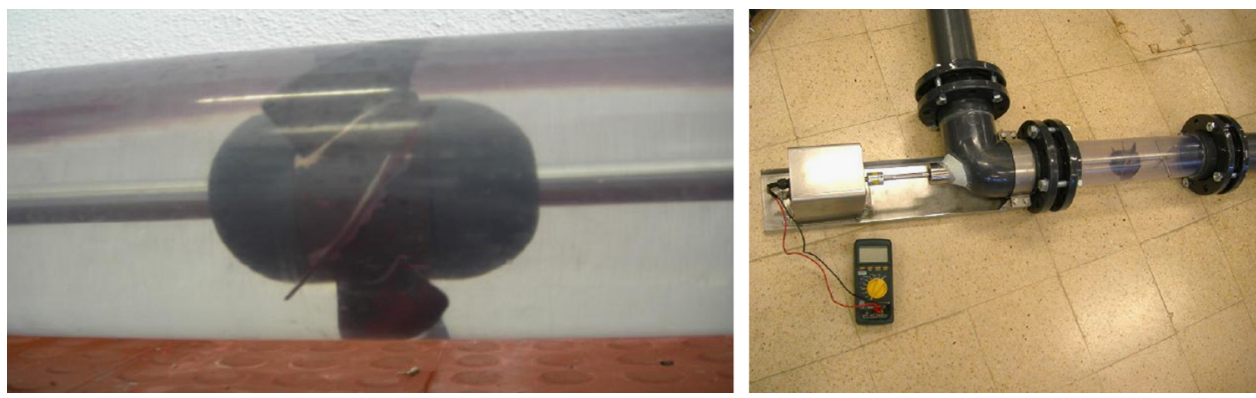

Fig. 5. Tubular propeller with 5 blades.

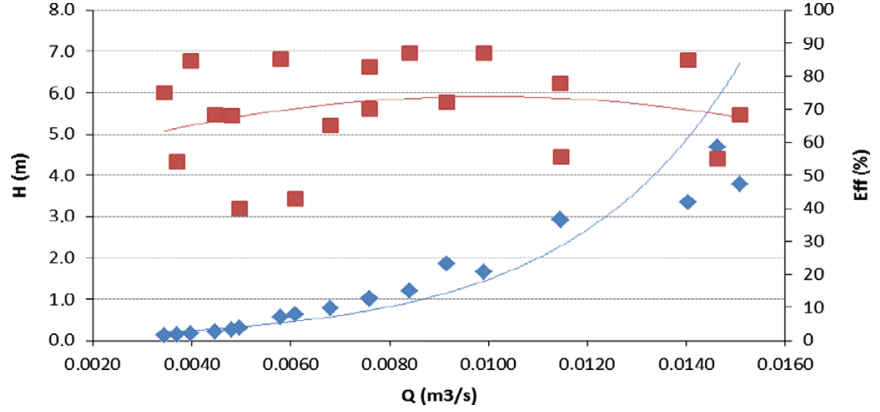

Fig. 6. Performance curves of head (lozenges) and efficiency (squares) versus discharge, for a runner with five blades and a diameter of $100 \mathrm{~mm}$.

output and efficiency. Even if the upstream water level is slightly higher than the top edge of the hub (about 1/4 of the blade length) the power output and efficiency of the HPM improve.

As an alternative solution for very small available discharge values, a tubular propeller with 5 blades (Fig. 5), which can be applied in a pipe system, has been developed at Instituto Superior Técnico-CEHIDRO, in the University of Lisbon (Ramos et al., 2009, 2012a-2012d).

Under lab conditions and for the internal diameter of $100 \mathrm{~mm}$, the tubular propeller with 5 blades (TP5B) was tested for different head and flow values in order to simulate the conditions found in a typical real water system (Fig. 5).

Additionally a mathematical approach was developed to assess the performance characteristics as shown in Figs. 6 and 7, obtained based on CFD simulations, which allow to compare head and mechanical power for a tubular propeller with the internal diameter of $100 \mathrm{~mm}$.

For power generation purposes, a $500 \mathrm{~W}$ with a DC permanentmagnet machine was also used. The use of a TP5B in water pipe systems demonstrated good hydro-mechanical efficiency values (40-80\%), representing a solution to be used for available flow energy that would be dissipated or wasted.

\section{Methodology}

The first step of the study consists on identifying the influence of suitable micro-hydro converters on the generated power solution and water discharge in order to find the best set-up to optimize joint management of the water-energy nexus. It is intended to both maximize the energy production and control the floods. Thus, according to each target demand, the height of the retention pond, the reduction factor and the output data are defined as a function of the volume.

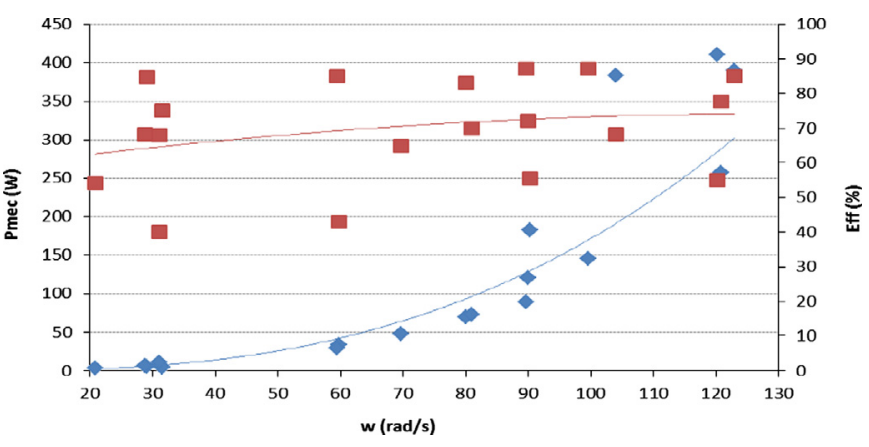

Fig. 7. Performance curves of mechanical power (lozenges) and efficiency (squares versus rotational speed for a runner with five blades and a diameter of $100 \mathrm{~mm}$.
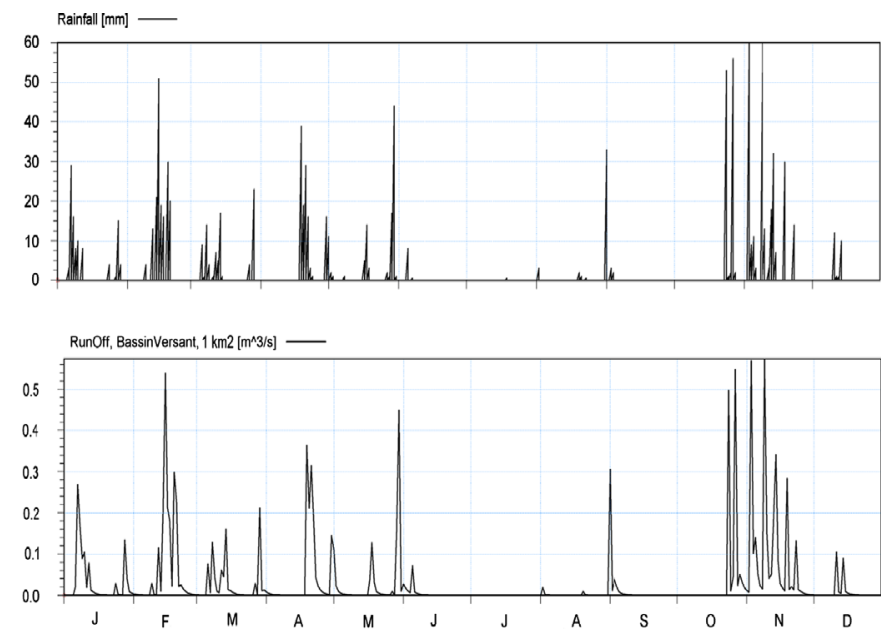

Fig. 8. Rainfall (mm) (top) runoff $\left(\mathrm{m}^{3} / \mathrm{s}\right)$ (bottom) for a small district Lisbon catchment area.

Source: Meteo.pt, 2012.

For the case study, the selected maximum heads are 3 and $10 \mathrm{~m}$. Those values correspond to the use of a wheel hydropower converter $(3 \mathrm{~m})$ and a tubular propeller $(10 \mathrm{~m})$ in order to take into account their respective limits of application. For this procedure, the rainfall and the size of urban area are defined. The size of the area under analysis is set at $1 \mathrm{~km}^{2}$.

Rainfall and runoff graphs data are inputs to the model from the meteorological Lisbon station for a typical climatic situation, as presented in Fig. 8. The feasibility analysis of producing energy with a micro-hydro converter is then analysed. It was considered the daily rainfall data of the year of 2011.

Fig. 9 shows the typical dynamic flow scenario in the complete drainage system composed by underground pipe flow and the respective piezometric line variation along the pipe profile. 

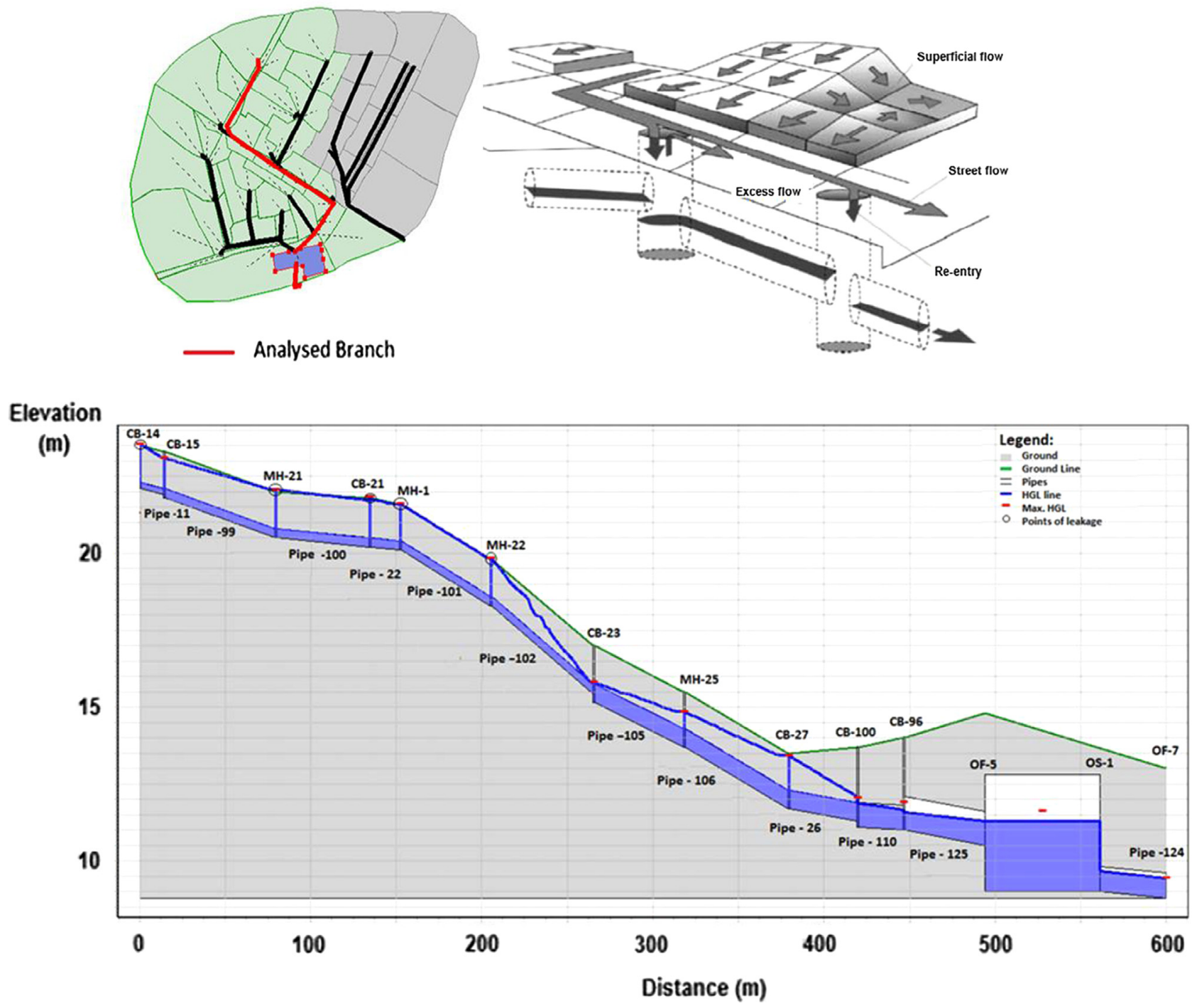

Fig. 9. Flood drainage system: plan view and type of flow (top); evaluation of the piezometric line along the analysed branch of the Lisbon area (bottom).

a

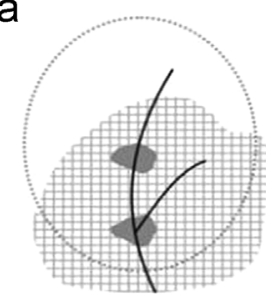

1st Step

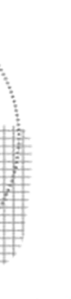

$==\mathbf{P i p e}$ flow \#再 Urbanization

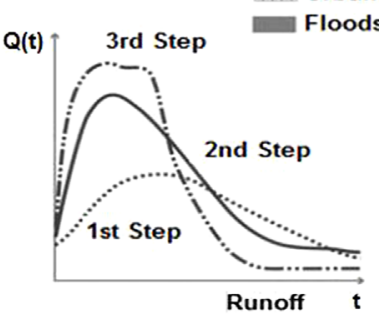

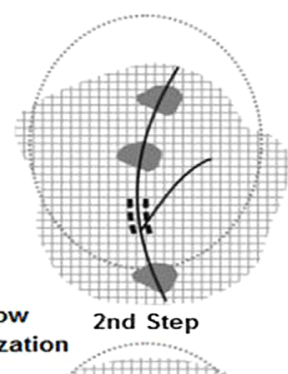

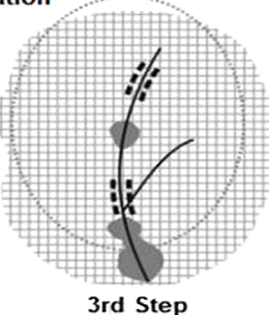

b
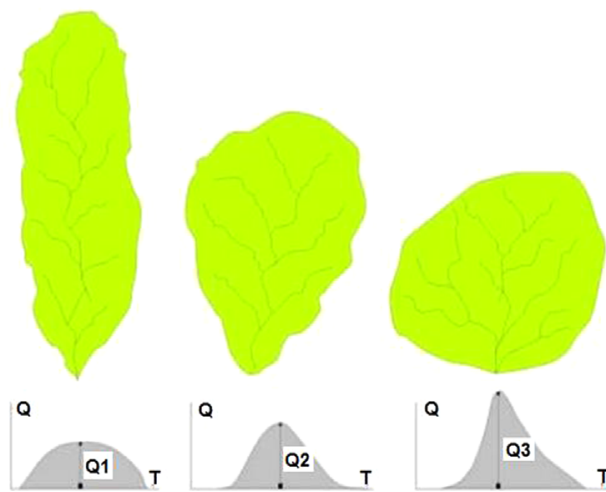

Q

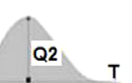

Fig. 10. Catchment basins: (a) Evolution of urbanization and runoff curves, (b) Basins geometry and respective runoff curves. Sources: adapted from Tucci, 2003 and adapted from Santos, 2011. 


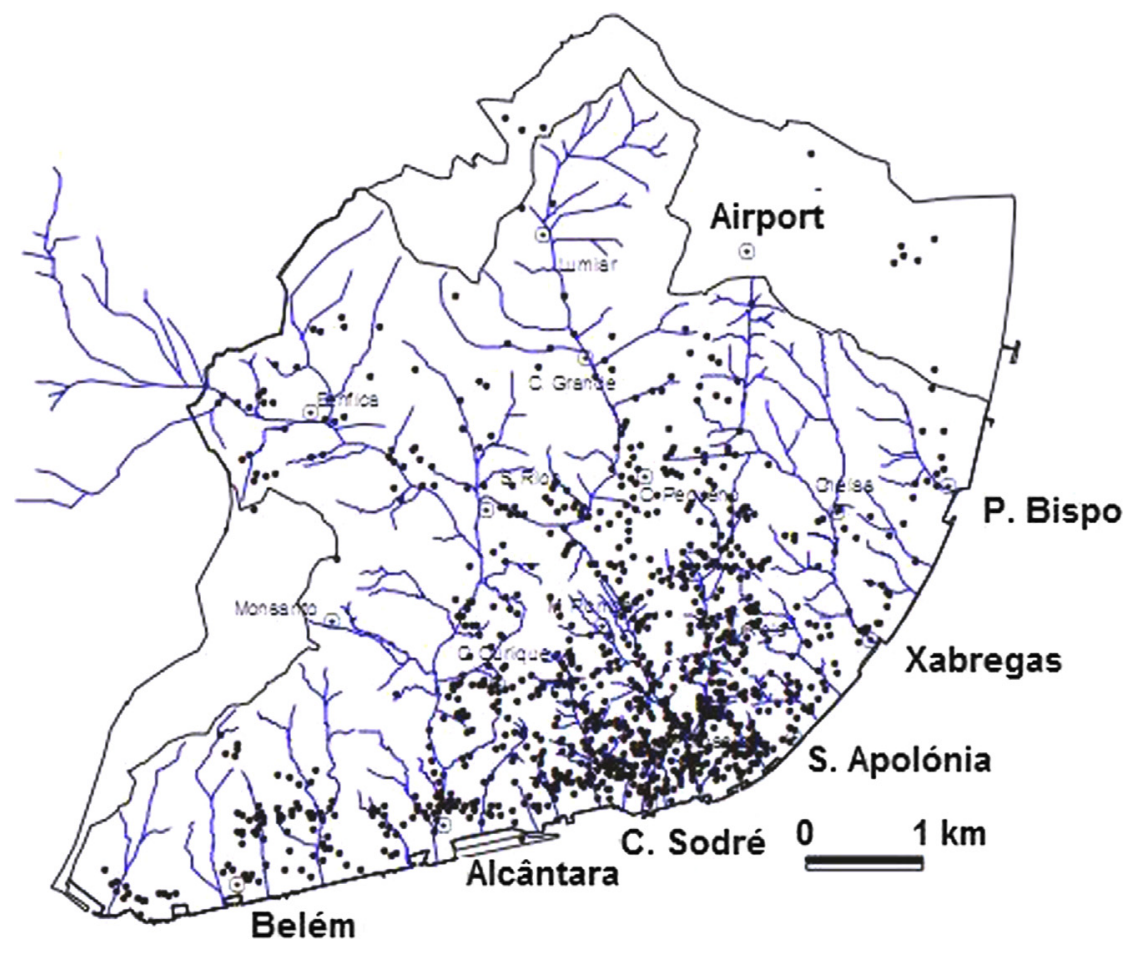

Fig. 11. Sites of flood events in Lisbon between 1918 and 2012.

Fig. 10 shows the influence that the urbanization can have in the runoff evaluation, as well as the catchment shape, in the maximum values.

Particularizing for the case of Lisbon, the type of flooding is similar to the one produced by a rounded basin geometry. The volumes of water are sufficient to stop traffic, as well as to inundate residential and commercial ground floors, causing problems on the daily commercial dynamics of a city due to its complex level of accessibilities.

In Lisbon, as well as in many other cities, the arising problem from flooding in urban areas is not a recent problem, and the frequency and intensity of the episodes have been getting worse in recent years. Some analyses have shown, for different periods, that the vast majority of flooded areas lie on old water lines (Fig. 11), a phenomenon explained by urban sprawl that led to the disappearance of watercourses, including the temporary flow regimes, through its plumbing, old beds being occupied by paved streets, buildings and other constructions. Fig. 11 shows the sites of floods in Lisbon in this last century. It is noticeable the correlation of the rounded shape of the Lisbon catchment basin and its consequence in the flood events, transforming in few minutes the downtown into an inundated zone.

\section{Results}

This analysis is done by observing the evolution of the total generated power, the total power deficit and the flow discharged downstream as function of the pond volume. In the sensitivity analysis, the volume varies from 510 to $25500 \mathrm{~m}^{3}$. The surplus capacity was not a variable of this study because it was not considered relevant to the main objective of this research. The influence of the flexibility of such a drainage system can be achieved with a joint management of runoff water and energy production using different target demands, reduction factors and different pond heights (available heads) of the retention ponds to find the best parameters for the pond volume that optimize the

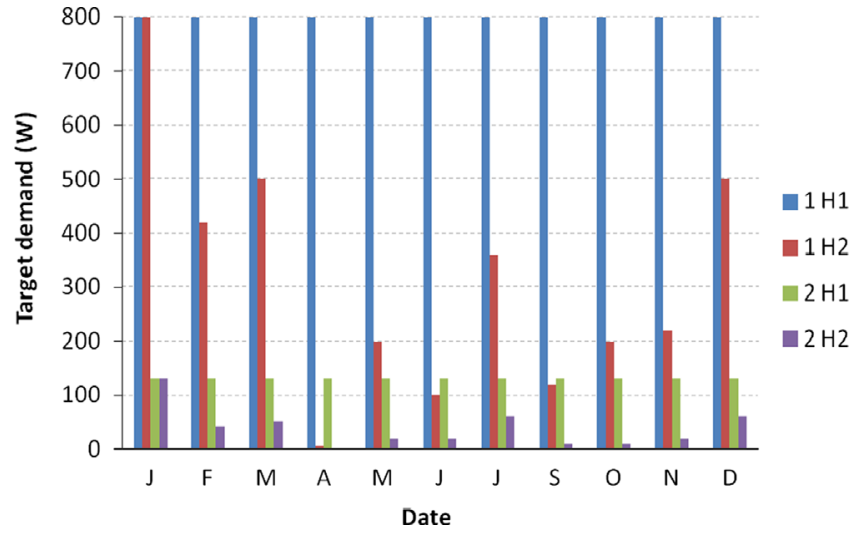

Fig. 12. Two selected power target demands for each hydropower station.

production of energy and minimize both the power deficit and the outlet runoff leaking.

\subsection{Analysis for two different target demands}

The results were analysed for the following target demands: Target 1 corresponds to a power installed of $800 \mathrm{~W}$ : a constant value of $800 \mathrm{~W}$ for the hydropower station 1 (Target 1 and hydropower $1=1 \mathrm{H} 1$ ) and a variable value with a maximum of $800 \mathrm{~W}$ for the hydropower station 2 (Target 1 and hydropower $2=1 \mathrm{H} 2$ ), depending on the season and on the monthly evolution of power demand (REN, 2012). The Target 2 demand is for a power installed of $130 \mathrm{~W}$ : a constant value of $130 \mathrm{~W}$ in hydropower 1 (target 2 and hydropower $1=2 \mathrm{H} 1$ ) and a variable value with a maximum of $130 \mathrm{~W}$ (target 2 and hydropower $2=2 \mathrm{H} 2$, respectively), as represented in Fig. 12.

In Fig. 13, the average per day of the total generated power for both Targets in a $10 \mathrm{~m}$-high pond is represented, as well as the maximum generated power, which corresponds to the average per day of the total target demand. The Target 2 shows how the 


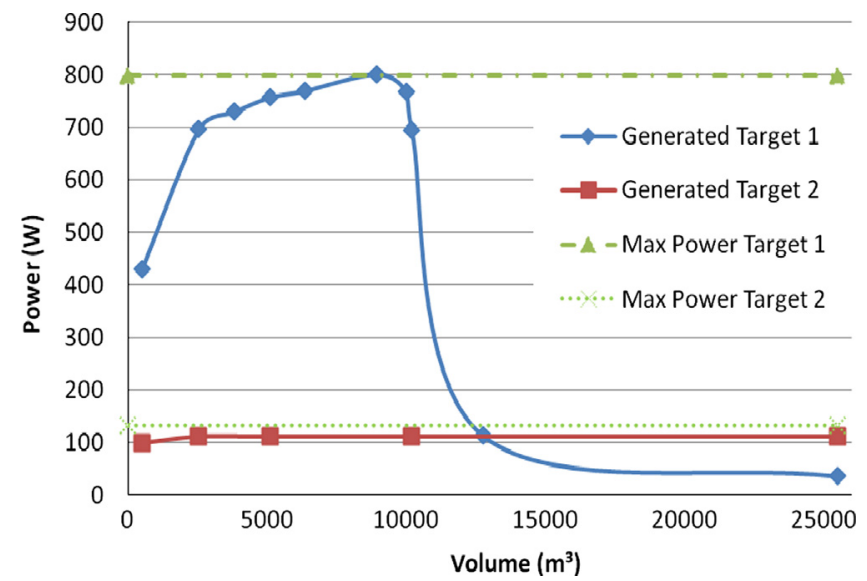

Fig. 13. Average per day of generated power as function of the pond volume for two different targets and for a $10 \mathrm{~m}$-high pond.

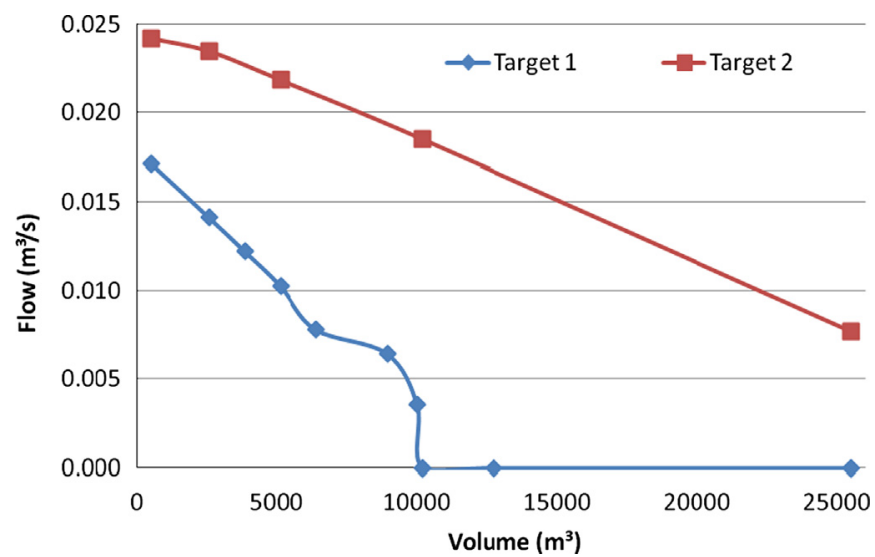

Fig. 14. Directly discharged flow as function of the pond volume for two different targets and for a $10 \mathrm{~m}$-high pond.

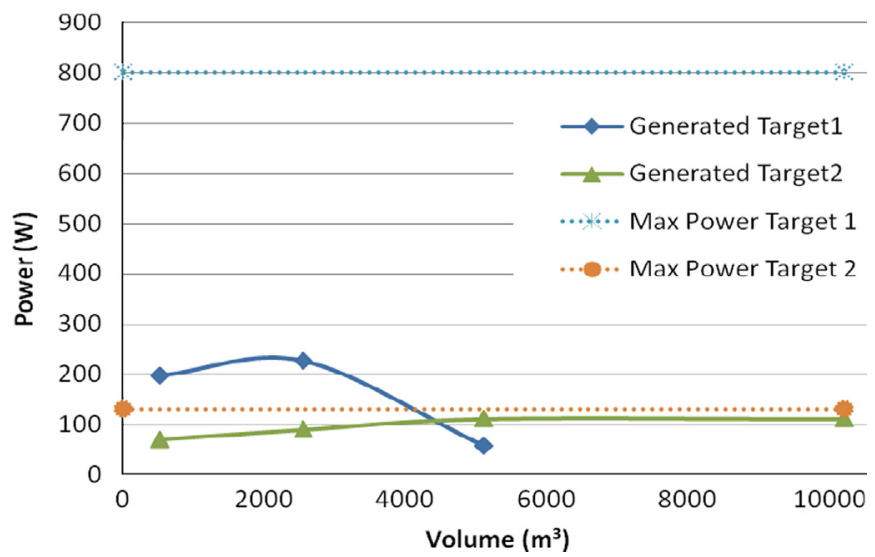

Fig. 15. Average per day of generated power as function of the pond volume for two different targets and for a $3 \mathrm{~m}$-high pond.

generated power follows the power demand. In Fig. 14, the flow directly discharged in the river is presented for both targets.

The set for Target 2 underestimates the capacity of the retention pond but the maximum intended power production is reached. However, the direct discharge is very significant when compared with the flow through hydropower stations $\mathrm{H} 1$ and $\mathrm{H} 2$. In fact, the target is lower than the production obtained if the total

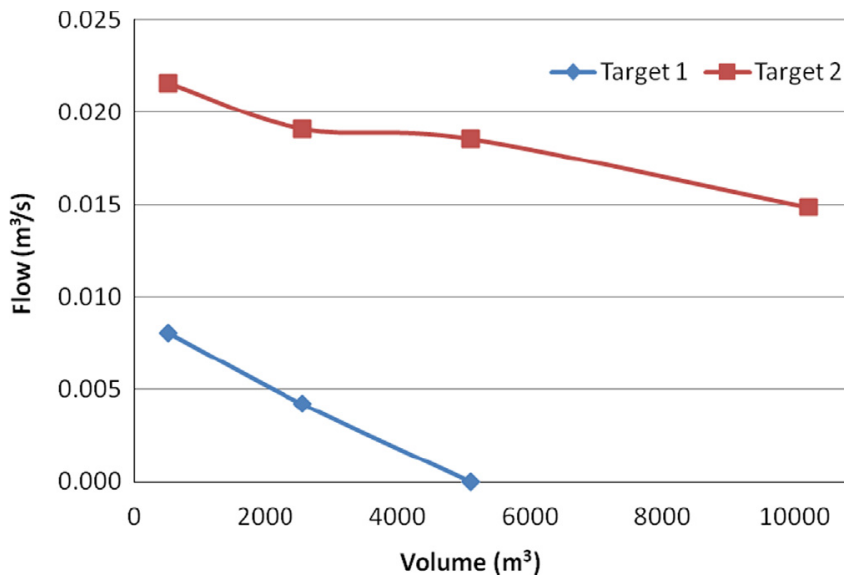

Fig. 16. Directly discharged flow as function of the pond volume for two different targets and for a $3 \mathrm{~m}$-high pond.

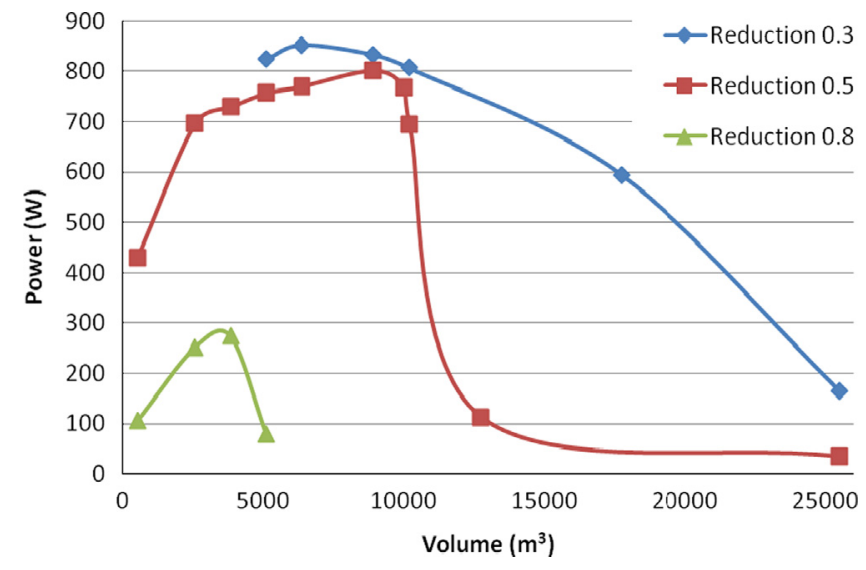

Fig. 17. Generated power as function of the pond volume for different reduction factors.

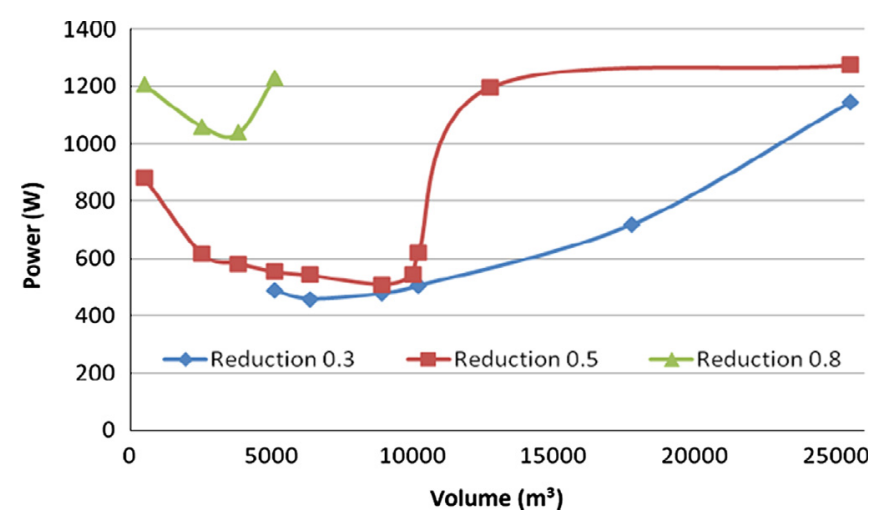

Fig. 18. Power deficit as function of the pond volume for different reduction factors.

amount of water was fully used, which means that the water losses are significant.

Target 1 is the one that best suits the system. A maximum generated power is reached at $8925 \mathrm{~m}^{3}$ (Fig. 13) but the water losses are still important. Thus, the most appropriate volume is $10000 \mathrm{~m}^{3}$ since the generated power is optimized without water losses.

Figs. 15 and 16 show the same type of analysis for a $3 \mathrm{~m}$-high pond. In this case, the flow has to be increased and the amount of water is not sufficient for the Target 1 . However, Target 2 is too low to be profitable and leads to important water losses as well. 
In the following steps, the study is focused on the $10 \mathrm{~m}$-high pond since its generated power is much higher than the one obtained with the $3 \mathrm{~m}$-high pond due to the low flow values of the case study.

\subsection{Impact of the reduction factor}

The reduction factor has a relevant influence on the optimization of the energy production. The principle is to slow down the water discharge for water levels below two-thirds of the global height of the pond. Hence, the instantaneous production is reduced but the water level is kept high for a longer time period, resulting in a better global production.

Figs. 17-19 present, respectively, the total generated power, the total power deficit and the directly discharged flow for three

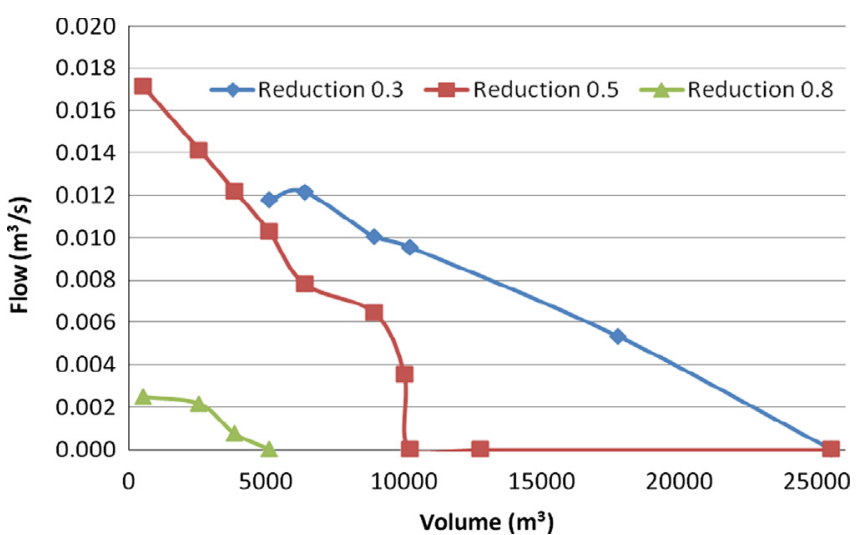

Fig. 19. Directly discharge flow as function of the pond volume for different reduction factors. different reduction factors $(0.3,0.5$, and 0.8$)$ for a $10 \mathrm{~m}$-high pond with the Target demand 1 .

The reduction factor 0.5 leads to a good production of energy and a low power deficit (around 40\%) when compared with the reduction factor equal to 0.8 . Besides, the directly discharged flow in the river decreases until 0 for volumes in which there is a better production.

Table 1

Characteristics of the micro-hydro converters.

\begin{tabular}{lll}
\hline & TP5B $(\boldsymbol{D}=\mathbf{1 0 0} \mathbf{~ m m})$ & HPM $(\mathbf{0 . 9 7} \mathbf{~ m}$ width $)$ \\
\hline Head & Low head $<10 \mathrm{~m}$ & Very low head $<3 \mathrm{~m}$ \\
Discharge & Small flow from 0.003 to & Medium flow about 0.05 to \\
& $0.016 \mathrm{~m}^{3} / \mathrm{s}$ & $0.420 \mathrm{~m}^{3} / \mathrm{s}$ \\
\hline
\end{tabular}

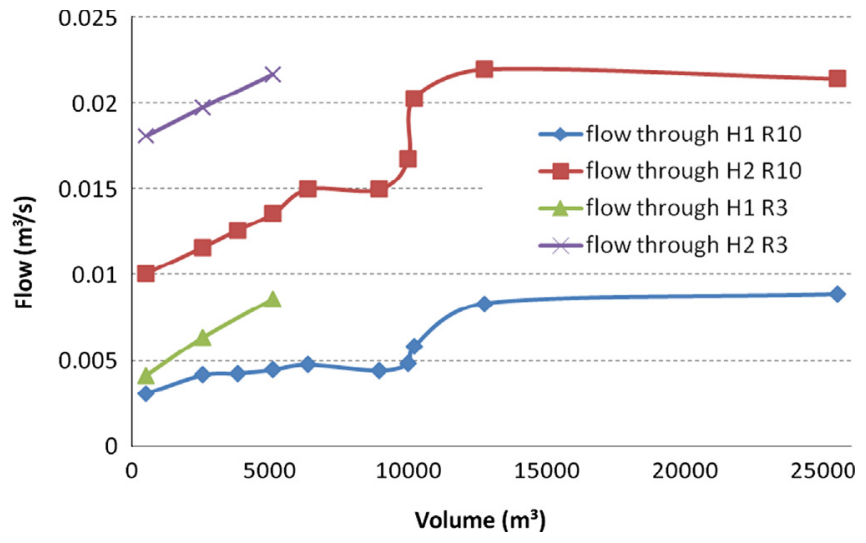

Fig. 21. Flows as function of the pond volume for two different heights of ponds
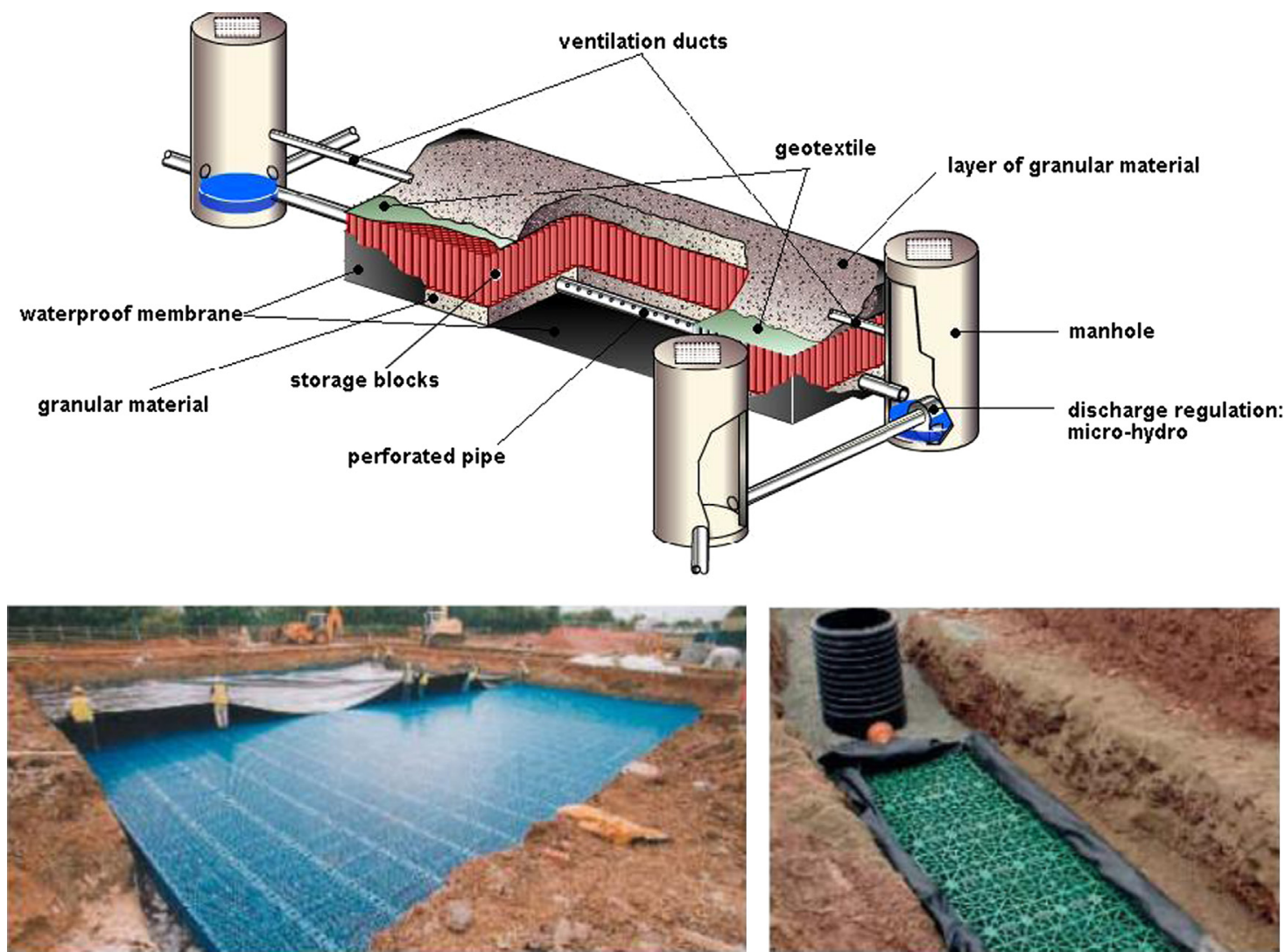

Fig. 20. Storage pond solutions in SUDS: (top) scheme of flood control system; (bottom) typical storage modular cells. Source: Santos, 2011, adapted from www.hydro-international.biz and www.marleyplumbinganddrainage.com. 


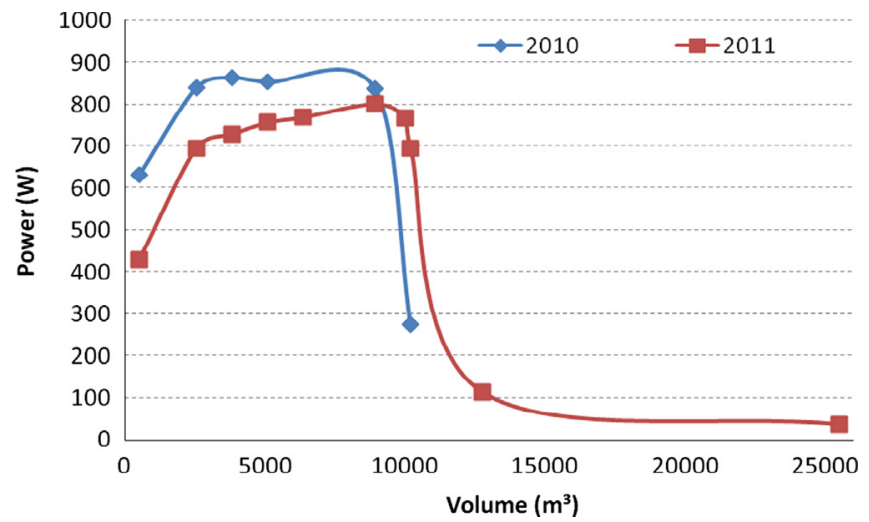

Fig. 22. Generated power as function of volume for two different rainfall data.

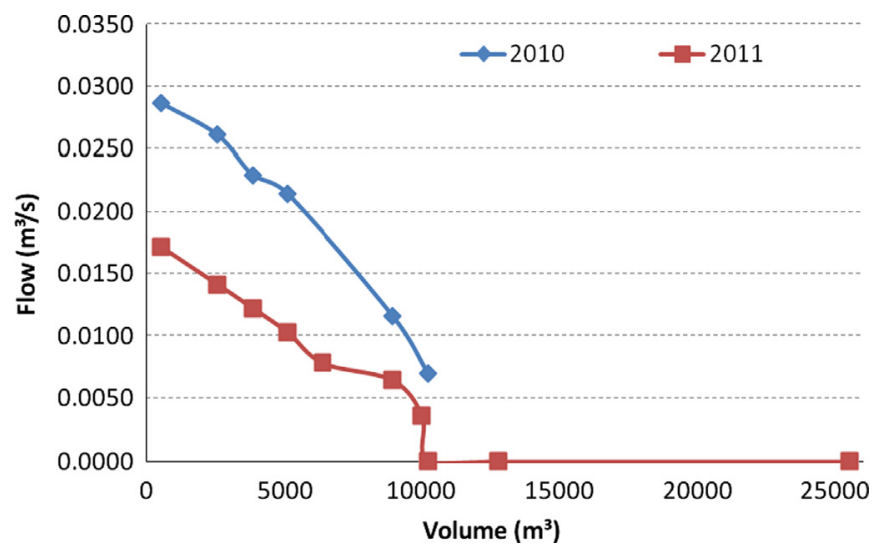

Fig. 23. Direct discharge as function of volume for two different rainfall data.

\subsection{Comparison between results and the range of application of micro-hydro converters}

The purpose of this study is to produce energy from a retention pond with a new micro-hydro converter installed at a pipe connection as illustrated in Fig. 20 (Andoh, 2012 and Santos, 2011).

The proposed energy converters will use low heads and each one has its own characteristics regarding the head and the discharge, which are presented in Table 1.

The flow values which are obtained through the outlet are small, as it is presented in Fig. 21 for different pond volumes.

Hence, in this case study, the tubular propeller (TP5B) seems more suitable for this type of water retention ponds, because of the low available flow values, and allows, consequently, a more continuous energy production along the all year.

\subsection{Consistency of results}

The methodology was also applied to the rainfall data of another year, 2010. The aim is to validate the consistency of results in order to choose the optimal volume for the design of a retention pond.

Figs. 22 and 23 present the generated power and the discharged flow for the two considered time series of rainfall (2010 and 2011). Through the observation of the results, a good correlation can be observed between both, confirming the pertinence of the results.

The descending of the generated power curve after the reached peak shows how important it is to avoid excess volumes in retention ponds design, in order to reduce the risk associated to not having enough power production in these joint water-energy management solutions in drainage systems.

\section{Conclusions}

The study gives clear results about water-energy nexus solutions for urban drainage systems based on flood retention ponds. These can be promising keys towards future smart water grids and cities, where the importance of the drainage system elasticity can change the actual paradigm of flood adaptation/mitigation. The runoff, which can lead to problematic floods, has also become a new energy source with several advantages for the social environment of urban areas. This new water-energy prototype can be implemented in existing runoff systems or in forthcoming urban design solutions.

In the analysed solutions, the higher the water level in the pond for the same volume the better the production of energy, because the available head is higher for the same turbine discharge. Indeed, flow values depend on rainfalls, so the control is operation-rainfall-runoff dependent. Also, there is a pond volume for which the solution is optimized for a given set of parameters and a pond volume interval can be set as the range of the system operation. In addition, the target demand should be adjusted regarding rainfalls and system characteristics.

A special effort of optimization is required to maximize the generated power and minimize the power deficit. The control of the water level was proved essential. Indeed, the reduction of the target demand according to the allowed water level improves considerably the energy production because the head is kept high. The case study reveals that this system could produce about $210 \mathrm{MWh}$ /year (for an average year hourly power of $800 \mathrm{~W}$ ). It should be noticed that the main purpose of the system is not the energy production, but the flood prevention in urban areas. A hydropower solution integrated in drainage systems can contribute to slow down the flow out of ponds, which allows a better prevention of floods, with a significant damping of the fast flow wave's propagation.

It is important to highlight that this hydraulic simulation methodology, with an optimized low-cost hydro solution and real-time flood control/adaptation, can improve the future drainage system elasticity in urban areas, with regional scale improvements. The methodology operates in a dynamic framework, depending on the pond volume, rainfall-runoff values and hydropower characteristics.

On the industrial side, the objective was to develop leading expertise in integrated management strategies (of water and energy), in a new perspective of the so-called future smart water systems based on new sustainable stormwater-power solutions. These solutions should take into account the control and adaptation of a joint management of flood-energy drainage systems under renewable innovative energy policy goals, particularly when the concern is the goal of non-carbon emissions, aiming to a higher share of renewable energy sources in a near future.

\section{Acknowledgements}

The authors wish to thank the Pays de la Loire region for the Envoleo grant and the European Erasmus commission for the Erasmus grant through the engineering school of Centrale Nantes, which enable the student to carry out the project. The authors also wish to thank the European Commission through CEHIDRO (Hydraulic Research Centre from the Civil Engineering Department of Instituto Superior Técnico (IST)-University of Lisbon) and research project EU HYLOW from the EU 7th Framework Program for Research and Technological Development, (Grant no. 212423), which contributed to the development of this research. 


\section{References}

Andoh, R., 2012. Engineering nature way, European project shares water knowledge. Hydro International.

Beaulieu, R.A., 2010. National Smart Water Grid: Integrated Solutions for Sustainable Fresh Water Suppy. Global Beau Publications.

Bizikova L., T. Neale, I. Burton, (2008). Canadian communities' guidebook for adaptation to climate change. Including an Approach to Generate Mitigation Co-benefits in the Context of Sustainable Development, first ed. Environment Canada and University of British Columbia, Vancouver. Catalogue No: En56226/2008E ISBN: 978-1-100-10839-1.

Breinholt, A., Santacoloma, P.A., Mikkelsen, P.S., Madsen, H., Grum, M., Nielsen, M.K. (2008). Evaluation framework for control of integrated urban drainage systems. In: 11ICUD, 11th International Conference on Urban Drainage, Edinburgh, Scotland, 31st August-5th September 2008. CD-ROM, University of Sheffield, Sheffield, UK.

Bruno, G.S., Fried, L., Hopwood, D., 2008. Focus on small hydro. Renewable Energy Focus 9 (6), 54-57. (November-December 2008).

Caxaria, G.A., Mesquita e Sousa, D., Ramos, H.M. (2011). Small Scale Hydropower: Generator Analysis and Optimization for Water Supply Systems. World Renewable Energy Congress 2011 (Theme: Hydropower Applications (HP))-8-11 May 2011, Linköping, Sweden.

DHI, 2009. Mike Basin User Manual. Hørsholm, Denmark.

Einfalt, T., Hatzfeld, F., Wagner, A., Seltmann, J., Castro, D., Frerichs, S., 2009. URBAS: forecasting and management of flash floods in urban areas. Urban Water Journal 6 (5).

Eum, H., Vasan, A., Simonovic, S.P., 2012. Integrated reservoir management system for flood risk assessment under climate change. Water Resources Management 26 (13), 3785-3802, http://dx.doi.org/10.1007/s11269-012-0103-4.

Hoekstra, A.Y., Chapagain, A.K., Aldaya, M.M., Mekonnen, M.M. (2009). Water Footprint Manual: State of the art 2009. Water Footprint Network: Enschede, the Netherlands.

Howe, C., Mitchell, C., 2012. Water Sensitive Cities. IWA Publishing, London.

Lindström, A., Granit, J. (2012). Large-scale Water Storage in the Water, Energy and Food Nexus Perspectives on Benefits, Risks and Best Practices. Josh Weinber (Ed.). Stockholm.

Madsen, H., Refsgaard, A., Falk, A.K., 2009. Energy optimization of well fields. Ground Water 47 (6), 766-771.

Makropoulos, C., Natsis, K., Liu, S., Mittas, K., Butler, D., 2008. Decision support for sustainable option selection in integrated urban water management. Environmental Modelling \& Software 23, 1448-1460.

Meteo.pt (2012). IP Portugal-〈http://www.meteo.pt/pt/oclima/acompanhamento/ index.jsp?selTipo $=g \&$ selVar $=$ rr\&selAno $=-1 \#\rangle$.

Pender, G., Néelz, S., 2007. Use of computer models of flood inundation to facilitate communication in flood risk management. Environmental Hazards 7 (2), $106-114$.

REN (2012). (National Electric Network) 〈http://www.centrodeinformacao.ren.pt/ PT/Informacao/Exploracao/Paginas/EstatisticaMensal.aspx $\rangle$.

Ramos, H.M., Borga, A., Simão, M., 2009. New design solutions for low-power energy production in water systems. Water Science and Engineering 2 (4), 69-84.
Ramos, H.M., Kenov, K.N., Vieira, F., 2011. Environmentally friendly hybrid solutions to improve the energy and hydraulic efficiency in water supply systems. Energy for Sustainable Development 15 (4), 436-442.

Ramos, H.M., Kenov, K.N., Pillet., B., 2012a. Stormwater storage pond configuration for hydropower solutions: adaptation and optimization. Journal of Sustainable Development 5 (8), 27-42. (ISSN 1913-9063 E-ISSN 1913-9071, Published by Canadian Center of Science and Education).

Ramos, H.M., Simão, M., Borga, A., 2012b. CFD and experimental study in the optimization of an energy converter for low heads. Energy Science and Technology 4 (2), 69-84.

Ramos, H.M., Simão, M., Kenov, K.N., 2012c. Low-head energy conversion: a conceptual design and laboratory investigation of a microtubular hydro propeller. ISRN Mechanical Engineering, 1-10, http://dx.doi.org/10.5402/2012/ 846206. (Article ID 846206).

Ramos, H., Simão, M., Borga, A., 2013. Experiments and CFD analyses for a new reaction microhydro propeller with five blades. Journal of Energy Engineering 139 (2), 109-117.

Ramos, J.S., Ramos, H.M., 2009. Sustainable application of renewable sources in water pumping systems: optimised energy system configuration. Energy Policy 37 (2), 633-643.

Santos, R.S. (2011). Urban Floods and Constructive Measures for Its Mitigation. M.Sc Thesis at IST.

Schneider, S., Müller, G., Saenger, N. (2011). Nutzung von geringen Fallhöhen zur Energiegewinnung - Untersuchungen an einer Wasserdruckmaschine (On using small head differences - Investigations on a hydraulic pressure machine). In: Annual Conference on Hydraulic Engineering 2011, Dresden (Germany).

Senior, J., Wiemann, P., Muller, G.U. (2008). The rotary hydraulic pressure machine for very low head hydropower sites. In: International Conference on Small Hydropower. Hidroenergia 2008: "On the crossroads", Bled, Slovenia11th-13th June.

Senior, J., Saenger, N., Müller, G., 2011. New hydropower converters for very-low head differences. Journal of Hydraulic Research 48 (6), 703-714. (ISSN 0022 1686).

Sommers, G.L., 2004. Hydropower resources. Encyclopedia of Energy 2004 325-332.

Talukdar, B., Deb, D., Srivastava, D.K., 2011. World Environmental and Wate Resources Congress 2011, 3978-3989, http://dx.doi.org/10.1061/41173(414)415.

Tingsanchali, T., 2012. Urban flood disaster management. Procedia Engineering 32 (2012), 25-37. (ISEEC).

Tucci, C.E.M., 2003. Inundations and urbain drainage. In: Tucci, C.E.M., Bertoni, J.C. (Eds.), Urbain Inundations in South America. Brasilien Association of Water Resources, Porto Alegre, Brasil, In Portuguese.

UK.Lee, J.G., Selvakumar, A., Alvi, K., Riverson, J., Zhen, J.X., Shoemaker, L., Lai, F., 2012. A watershed-scale design optimization model for stormwater best management practices. Environmental Modelling \& Software 37, 6-18. (November).

Vieira, F., Ramos, H.M., 2008. Hybrid solution and pump-storage optimization in water supply system efficiency: a case study. Energy Policy 36 (11), 4142-4148.

Wegehenkel, M., Kersebaum, K.C., 2008. A first assessment of the impact of climate change on discharge and groundwater recharge in a catchment in Northeastern Germany. Journal of Biometeorology 10, 274-281.

Wiemann, P., Müller, G., James Senior, J., 2009. Review of current developments in low head, small hydropower, Hylow project. University of Southampton. 